\title{
Expression of ERG protein in prostate cancer: variability and biological correlates
}

\author{
Gustavo Ayala', Anna Frolov ${ }^{2,3}$, Deyali Chatterjee ${ }^{3}$, Dandan $\mathrm{He}^{3}$, Susan Hilsenbeck ${ }^{2}$ \\ and Michael Ittmann ${ }^{3,4}$ \\ ${ }^{1}$ Department of Pathology and Laboratory Medicine, University of Texas Health Sciences Center Medical School, \\ Houston, Texas, USA \\ ${ }^{2}$ Dan L. Duncan Cancer Center, Houston, Texas, USA \\ ${ }^{3}$ Department of Pathology and Immunology, Baylor College of Medicine, One Baylor Plaza, Houston, \\ Texas 77030, USA \\ ${ }^{4}$ Department of Veterans Affairs, Michael E. DeBakey VA Medical Center, Houston, Texas 77030, USA
}

\author{
Correspondence \\ should be addressed \\ to M Ittmann \\ Email \\ mittmann@bcm.edu
}

\begin{abstract}
Prostate cancer is the second leading cause of cancer-related death of men in the USA. The TMPRSS2IERG (TIE) fusion gene is present in approximately $50 \%$ of prostate cancers and promotes tumor progression in vivo. The presence of the TIE fusion gene is strongly associated with the expression of ERG protein, but emerging evidence indicates a significant interfocal and intrafocal variability in the levels of ERG protein expression. We therefore analyzed ERG protein expression by image analysis to objectively quantitate the extent of such heterogeneity, and confirmed significant interfocal and intrafocal variability of ERG protein expression levels in cancer expressing ERG. To define the pathways associated with ERG and its variable expression in prostate cancer, we have analyzed the correlations of ERG expression, as evaluated by immunohistochemistry, with 46 key proteins associated with signal transduction, transcriptional control, and other processes using a large tissue microarray with more than 500 prostate cancers. We found a significant correlation of ERG expression with the markers of activation of the PI3K, MYC, and NFKB pathways, which had previously been linked directly or indirectly to ERG expression. We have also identified significant correlations with novel proteins that have not been previously linked to ERG expression, including serum response factor, the p160 coactivator SRC1, and Sprouty1. Notably, SKP2 only correlated with a high level of ERG protein expression. Thus ERG expression is variable in prostate cancer and is associated with activation of multiple pathways and proteins including several potentially targetable pathways.
\end{abstract}

\section{Key Words \\ - prostate cancer \\ - TMPRSS2/ERG \\ - MYC \\ $\checkmark$ PTEN \\ - NFKB}

\section{Introduction}

Prostate cancer remains the most common malignancy affecting men, and the second leading cause of cancerrelated death of men in the USA. It is a heterogeneous disease, and the biology of various subtypes is still poorly understood. The pathways that are altered at high frequency in specific patient tumor types need to be better defined to optimize individually targeted therapy. Over the past 8 years, important progress has been made in the subclassification of prostate cancer, in particular the finding that the TMPRSS2/ERG (T/E) fusion gene is present

Published by Bioscientifica Ltd. 
in approximately $50 \%$ of prostate cancers. Results of experiments carried out on prostate cancer cells containing the $T / E$ fusion (Tomlins et al. 2005) indicate that the TMPRSS2 promoter, which contains androgen receptor (AR)-responsive promoter elements (Lin et al. 1999), increases ERG expression in response to androgens. The ubiquitous activity of AR in prostate cancer cells thus results in the constitutive expression of $E R G$ fusion transcripts and ERG protein. We have demonstrated that the $T / E$ fusion gene can enhance proliferation, invasion, and motility of prostate epithelial cells (Wang et al. 2008). More importantly, stable knockdown of the $T / E$ fusion mRNA in VCaP cells inhibits tumor growth in vivo, indicating that the $T / E$ fusion gene is a potential therapeutic target which is present in the majority of prostate cancers (Wang et al. 2008). More recently we have shown that highly specific knockdown of the $T / E$ fusion gene with siRNAs delivered via nanoliposomal vectors substantially decreases the growth of established tumors, confirming the importance of the $T / E$ fusion gene in cancer progression in vivo (Shao et al. 2012).

The pathways and proteins implicated in the ability of the ERG oncoprotein to promote prostate cancer progression have been a focus of active investigation. Prostate cancers with ERG expression have been shown to activate multiple proteins and pathways such as Ezh2, Wnts, TGFB, and SOX9 (Sun et al. 2008, Tomlins et al. 2008, Gupta et al. 2010, Yu et al. 2010, Brase et al. 2011, Vainio et al. 2011, Magistroni et al. 2011, Cai et al. 2013, Massoner et al. 2013, Tian et al. 2013, Wu et al. 2013). We have shown that the $T / E$ fusion gene increases NFKB-mediated transcription via increased phosphorylation of NFKB p65 on Ser536 (Wang et al. 2011). Results of correlative studies of human prostate cancers reveal a strong association of ERG expression with loss of PTEN, and results of studies using mouse models reveal that ERG expression and PTEN loss synergistically promote progression of prostate cancer (Han et al. 2009, King et al. 2009, Chen etal. 2013, Leinonen et al. 2013). Thus alterations in a number of key pathways and proteins important in tumor progression have been linked to the presence of ERG expression.

One aspect of the biology of the $T / E$ fusion gene that has received limited attention to date is the substantial variability of ERG protein expression levels in cancers containing the T/E fusion. Detection of the presence of the protein product of the $T / E$ fusion gene in a focus of prostate cancer by immunohistochemistry (IHC) is strongly associated with the presence of the $T / E$ fusion gene in that focus, although less common variant translocations driving ERG expression have been identified. However, there can be substantial intrafocal variability in the levels of ERG expression (Mertz et al. 2013, Minner et al. 2013). To evaluate objectively the variability of ERG protein expression in prostate cancers, we have carried out a multispectral image analysis of ERG expression in a cohort of more than 500 radical prostatectomies that we have studied extensively over the last 10 years. In addition, we have examined the correlation of 46 proteins and tumorspecific factors in this same cohort with ERG expression. The results of our studies confirm the extent of variability of ERG expression in prostate cancer. The results from correlative studies have confirmed the known or inferred associations with several important pathways/proteins that had previously been linked directly or indirectly to ERG expression, including the PI3K, MYC, and NFאB pathways. We have also identified significant correlations with novel proteins that have not, to our knowledge, been previously linked to ERG expression, including serum response factor (SRF), the p160 coactivator SRC1 and Sprouty1. Importantly, we have found differential correlations based on the level of ERG expression consistent with a significant biological effect of ERG expression levels. In particular, SKP2 only correlated with a high level of ERG protein expression. Thus ERG expression is a variable in prostate cancer and is associated with the activation of multiple pathways and proteins, including several potentially targetable pathways.

\section{Materials and methods}

\section{IHC evaluation}

Tissues required for analysis were collected with informed consent under and Institutional Review Board approved protocol. IHC for ERG expression in the tissue microarray (TMA) has been described previously (Wang et al. 2011). Briefly, antigen retrieval was carried out with heat using high $\mathrm{pH}$ Tris/borate/EDTA. The slides were incubated with a 1:100 dilution of rabbit anti-ERG MAB (clone EPR3864, Abcam, Cambridge, MA, USA). The anti-rabbit HRP antibody was applied for $16 \mathrm{~min}$ at room temperature and detected using a ChromoMap DAB Detection System (Ventana, Tucson, AZ, USA). The slides were then counterstained with hematoxylin. The same primary antibody has been used in other studies as well. In our initial study, ERG staining was scored visually as positive or negative, with any staining of cancer nuclei was classified as positive regardless of intensity or extent based on the finding that even weak expression was correlated with the presence of the $T / E$ fusion gene (Park et al. 2010). To more

Published by Bioscientifica Ltd 
quantitatively evaluate ERG protein expression, each TMA slide was imaged using the Vectra-Inform Image Analysis System (Cambridge Research \& Instrumentation, Inc., Hopkinton, MA, USA), an automated multispectral slide analysis system. $4 \times$ scans were obtained to detect the TMA, and $20 \times$ multispectral images were acquired from each core for IHC scoring of ERG with inForm. The inForm Software supports image analysis projects by combining automated image processing with advanced object recognition and data analysis tools. Using image segmentation technology, we trained the system to recognize and distinguish significant histological features, including cancerous epithelial cells, stroma, and luminal spaces, in entire images. Cellular segmentation was used to detect cellular components such as nuclei and cytoplasm. After segmenting tissues and nuclei, we used the IHC scoring tool to score the intensity of ERG staining in cancer nuclei. We selected four bins, ranging from 0 to $3+$, to score ERG in cancerous epithelium with ERG staining. This was then applied to all images, yielding, for each case, a 'distribution' of staining intensity represented as the fraction of cancer nuclei in each bin.

Over the last 10 years, we have carried out numerous studies of protein expression and biological alterations in prostate cancer using a large TMA of radical prostatectomy specimens containing more than 500 prostate cancers. Most of these studies have been published (Yang et al. 2002, Agoulnik et al. 2003, 2005, 2006, Ayala et al. 2003a,b, 2004, 2013a,b, Li et al. 2003, 2004a,b, 2006, 2007, 2009a,b, Kwabi-Addo et al. 2004, McAlhany et al. 2004, Dai et al. 2005, Haqq et al. 2005, Knudsen et al. 2005, Zhou et al. 2005, Cordon-Cardo et al. 2007, Hodgson et al . 2011, Yu et al. 2011, Ding et al. 2013, Qin et al. 2013) and the 46 biomarkers evaluated in this study are summarized in Table 1. For most markers, staining was quantitated in tumor cells in the appropriate subcellular compartment (nuclear/cytoplasmic) after IHC using a multiplicative index of staining intensity $(0-3)$ and extent $(0-3)$, yielding a ten-point staining index (0-9). For other markers, such as Ki67 and TUNEL, stained cancer cells in each core were counted while for CD34 and c-KIT positive cells in the stroma were counted. Not every tumor was scored on every marker, in part due to exhaustion of tumor, folds, other artifacts, etc.

\section{Statistical analysis}

ERG expression was summarized in three ways - by visual assessment as a dichotomous variable, as a distribution with four levels, and as the Mean Bin, computed as the
Table 1 Markers evaluated for association with ERG expression

\begin{tabular}{|c|c|c|c|}
\hline Transcription & Signaling & Microenvironment & Others \\
\hline$A R$ & PTEN & CD34 & ADRB2 \\
\hline SRC1 & INPP4b & Semaphorin 4F & ASCT2 \\
\hline$S R C 2$ & $\mathrm{AKT}$ & c-KIT & CAS \\
\hline$S R C 3$ & P-AKT & & CAV1 \\
\hline COUPTFII & FKHR & Cell cycle & FGFR4 \\
\hline$E R$ & P-FKHR & Cyclin D1 & HAI1 \\
\hline$D A X 1$ & GSK3B & p27 & VEGFR3 \\
\hline$N C O R$ & P-GSK3B & SKP2 & SPINK1 \\
\hline REGG & GGAP2 & & GLIPR 1 \\
\hline$S R F$ & NFкB p65 & Proliferation/death & PIN1 \\
\hline$M Y C$ & NFKB p65 P-276 & Ki67 & WFDC1 \\
\hline p53 & NFKB p65 P-536 & TUNEL & \\
\hline \multirow[t]{2}{*}{ PIM2 } & PKC-E & & \\
\hline & Sprouty1 & & \\
\hline
\end{tabular}

frequency weighted average of the bin intensities. Distributional patterns of ERG expression were visualized using a Heatmap, with additional side bars to display corresponding values for visually assessed ERG status and Mean Bin ERG. Agglomerative hierarchical clustering with complete linkage was used to cluster cases with similar distributional patterns. The Kolmogorov-Smirnov (KS) statistic, which quantifies the distance between two empirical distribution functions and is sensitive to differences in both location and spread, was used as the distance metric to compute the 'distance' between each case and every other case. Clustering and heat mapping were performed using R. The Mann-Whitney $U$ test was used to test for differences in the levels of studied markers between visually ERG-positive and -negative cancers. The association of average ERG expression (Mean Bin) with clinical and pathological variables as well as the panel of 46 previously studied TMA biomarkers was evaluated using Spearman's rank correlation. There was no formal adjustment for multiple comparisons, although a more stringent $\alpha=0.01$ was used. Kaplan-Meier survival curves and log rank tests were used to evaluate the effect of ERG positivity on biochemical recurrence-free survival (RFS) and the effect of other biomarkers on RFS within each ERG visual expression group model. The associations were summarized by hazard ratios (HRs) and 95\% CIs, estimated by Cox proportional hazards regression. Candidate biomarkers were dichotomized as 'low' or 'high' using previously determined cutpoints. Unless otherwise specified, $P$ values of $\leq 0.05$ were considered statistically significant. Correlations and statistical comparisons were performed using the SPSS Software package (IBM SPSS Statistics, version 20.0, Armonk, NY, USA).

Published by Bioscientifica Ltd 
A
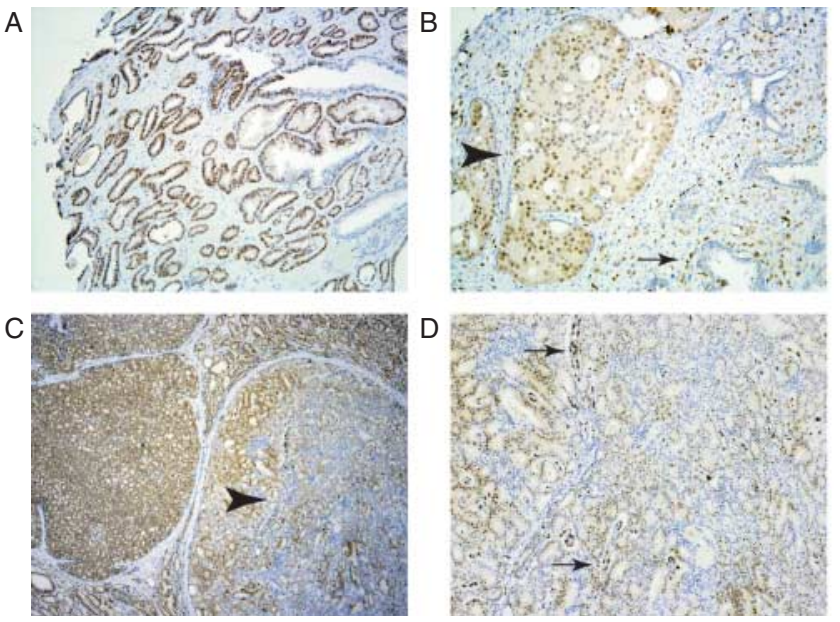
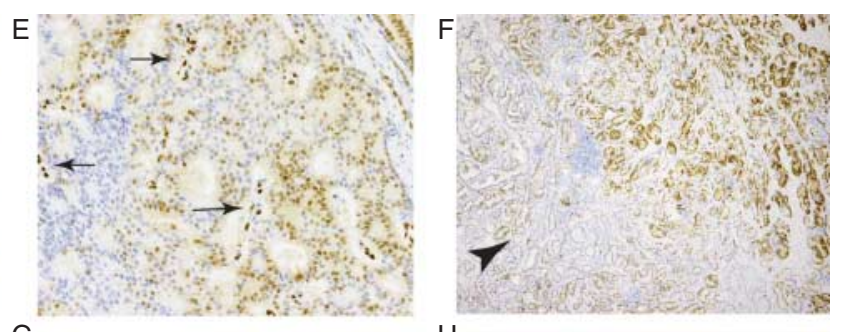

G

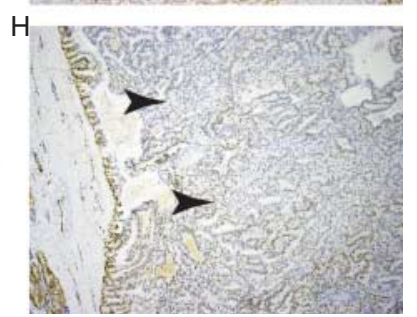

\section{Figure 1}

Immunohistochemical analysis of ERG expression in prostate cancers. ( $A$ and $B$ ) ERG expression in a tissue microarray (TMA). Some cancers showed uniform strong expression $(A, 40 \times$ ) while other cancers on the same TMA slide showed distinctly lower staining overall, and in some cases substantial intrafocal variability $(B, 100 \times)$. The arrowhead indicates a cribiform tumor nodule with variable ERG staining. The arrow indicates ERG staining in endothelial cells which is uniformly strong. (C, D, E, F, G and H)

\section{Results}

\section{Variability of ERG expression levels in prostate cancer expressing the ERG oncoprotein}

In previous studies, we have carried out IHC for ERG expression using a large TMA of cancers specimens from radical prostatectomies performed to treat clinically localized prostate cancer (Wang et al. 2011). As in most studies in the literature, prostate cancer cases were classified as positive for ERG expression if distinct staining was seen in cancer cell nuclei of any core, because even weak expression is correlated with the presence of the $T / E$ fusion gene (Park et al. 2010). However, we noted differences in staining intensity between cases stained on the same TMA slide (Fig. 1A and B). It was also noted that in some cases, there was a substantial variability of expression between tumor nuclei within a single cancer (intrafocal variability; Fig. 1B). To better understand the extent of such variability, we evaluated ERG expression in 16 consecutive radical prostatectomy specimens by IHC. In each case, the section with the largest percentage of tumor from the radical prostatectomy specimen was used for IHC. Ten cases stained positively for ERG. As in the TMA, we noted substantial variability in staining intensity between different cancers and within a single cancer focus. We quantitated the expression of ERG protein in cancer nuclei visually as $0,1+, 2+$, or $3+$ and estimated the Printed in Great Britain
ERG staining in cancer foci in radical prostatectomy specimens. (C, 40 $\times)$ Heterogeneous staining in a cribiform nodule of cancer (arrowhead). Note strong uniform staining in adjacent tumor nodule. (D, $100 \times$ and $E, 400 \times$ ) Heterogeneous staining with retained strong staining of endothelial cells (arrows). ( $\mathrm{F}, \mathrm{G}$ and $\mathrm{H}$ ) Cancers with weaker staining in the center of the tumor (arrowheads).

percentage of cancer cells with each staining intensity throughout the section. As shown in Fig. 2, there was substantial variability in staining intensity between the ten cases. Examples of variable staining are shown in Fig. 1C, D, E, F, G and $\mathrm{H}$. We noted that in several cases, there was a tendency to stain more strongly at the

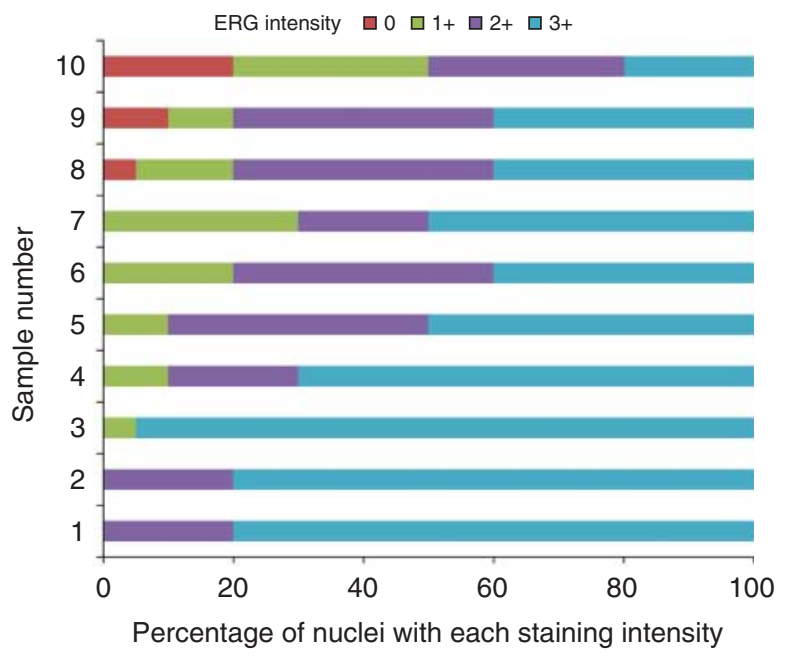

Figure 2

Analysis of ERG expression in prostate cancers by visual quantitation. Ten tumors from radical prostatectomy specimens with ERG staining by IHC were scored for staining intensity in cancer nuclei $(0,1+, 2+$, or $3+)$. The percentage of nuclei with each staining intensity was estimated to the nearest $5 \%$.

Published by Bioscientifica Ltd 
A

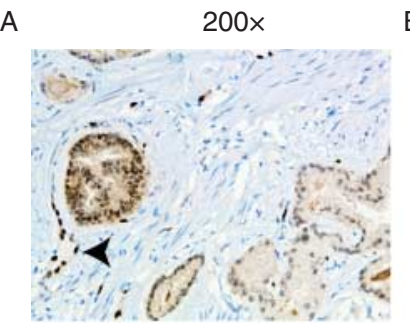

\section{.}
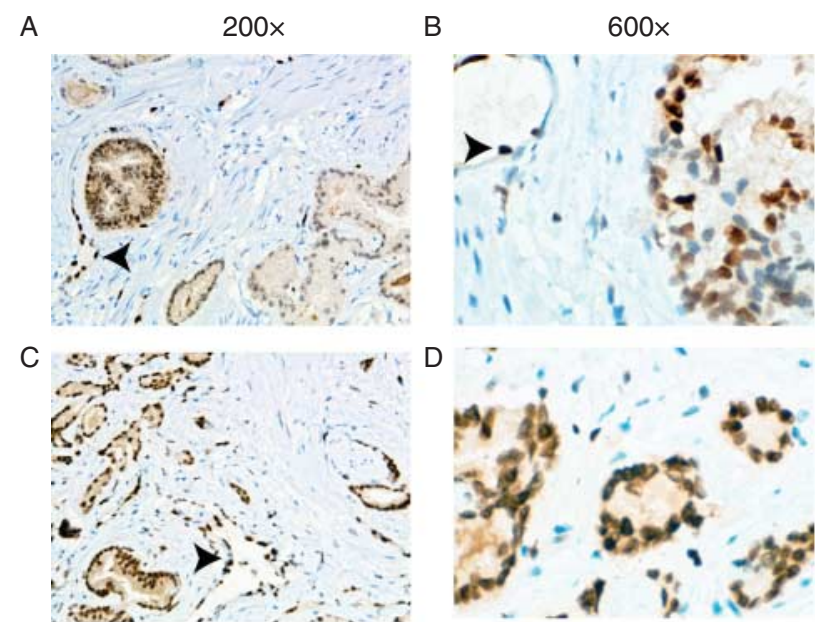

$\mathrm{E}$
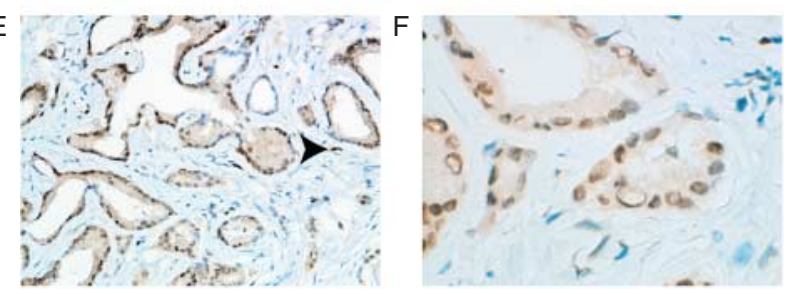

Figure 3

Immunohistochemistry with anti-ERG antibody using rapidly fixed prostatectomy tissues. Prostate cancer tissues were snap frozen in liquid nitrogen within $15 \mathrm{~min}$ of surgery and a thin slice removed was then fixed overnight in formalin, embedded, and ERG IHC performed. (A) Intrafocal variability. Weakly staining tumor is on the right with strongly staining tumor on the left. A blood vessel is indicated by the arrowhead. (B) Intrafocal variability. A tumor with variable staining within a single focus, ranging from negative to strong. An endothelial cell with strong staining is indicated by the arrowhead. (C, D, E and F) Interfocal variability. (C and D) Medium and high power views of a cancer with uniform strong staining similar to the staining intensity of endothelial cells. ( $E$ and F) Cancer with medium staining. Endothelial cells are indicated by the arrowheads. Magnifications are shown at top.

edge of tumors (Fig. 1F, G and H). This is unlikely to be an artifact of fixation because higher staining was seen both on the inner and outer (capsular) sides of the tumor, areas of strong staining often surrounded areas with weak or no staining, and staining of ERG in endothelial cells remained quite strong adjacent to cancer cells with deceased staining.

To confirm that the variable protein levels were not an artifact of delayed or poor fixation, we took prostate cancer tissues that had been snap frozen in liquid nitrogen within $15 \mathrm{~min}$ of surgery and took a thin slice that was then fixed overnight in formalin, embedded, and ERG IHC performed. As shown in Fig. 3, we still observed both interfocal and intrafocal variability of ERG expression in these rapidly fixed tissues. It should be noted that if IHC protocols are optimized to give a maximal ERG signal, as

is desirable for clinical use, the variable expression may be far less apparent than reported in this study.

\section{Image analysis of ERG expression in prostate cancer}

Given the substantial variability in staining, we carried out image analysis using multispectral imaging to quantify the extent of variable staining objectively. This analysis allowed us to determine the intensity of staining in cancer nuclei on a cell-by-cell basis, with each nucleus binned into one of four expression levels $(0,1+, 2+$, or $3+)$. The mean intensity of ERG staining was then determined for each cancer (ERG Mean Bin) based on the mean of all cancer nuclei. This analysis is shown in Fig. 4 in the Mean Bin row, with the lowest mean intensity shown in blue and the highest in red. The visual image quantitation data for each case is also shown. There was a very strong, although not perfect, correlation between the visual classification and the Mean Bin scores $(r=0.797$, $P<0.001)$. We then carried out hierarchical clustering of the distributions of staining, using the KS statistic as the

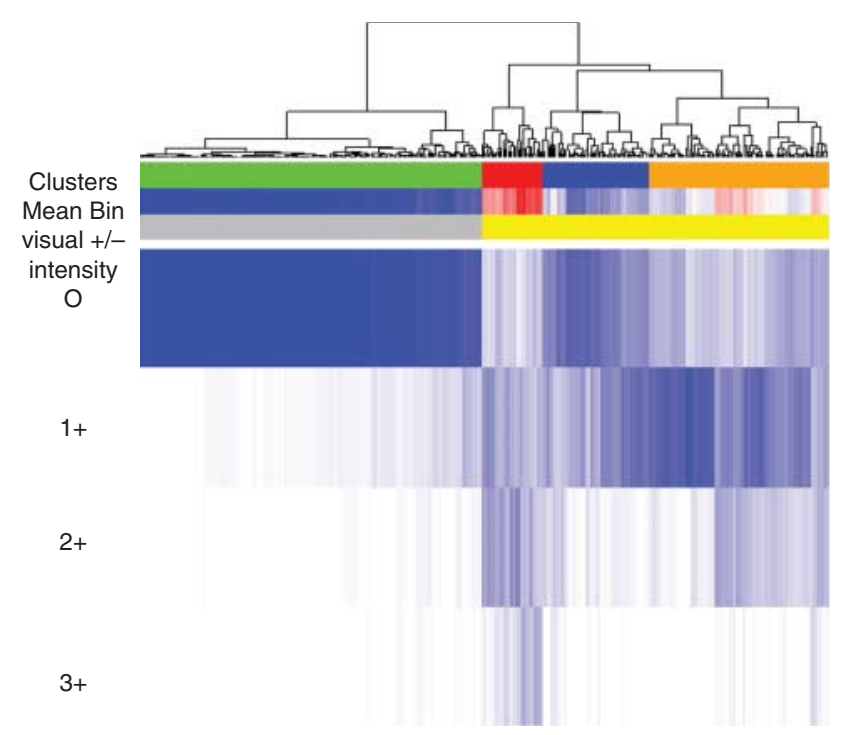

Figure 4

Examination of ERG expression in prostate cancers by image analysis. ERG expression was evaluated by immunohistochemistry of a prostate cancer tissue microarray as described previously. Expression was evaluated visually and classified as positive if any staining was seen in cancer nuclei. Expression was also quantitated by image analysis of all cancer nuclei. We selected four bins from 0-3+ to score ERG in cancerous epithelia with ERG staining, which was then applied to all images. Among cases with any visually positive staining there was substantial variability between tumors and within each tumor. The mean staining (Mean Bin) was calculated for each case. Cluster analysis of quantitative expression was then carried out for identification of four cluster groups indicated by green (negative), blue (low) orange (medium), and red (strong).

Published by Bioscientifica Ltd 
Table 2 Markers associated with ERG expression

\begin{tabular}{|c|c|c|c|c|}
\hline \multirow[b]{2}{*}{ Group } & \multirow{2}{*}{$\begin{array}{l}\text { Protein or } \\
\text { factor }\end{array}$} & \multirow{2}{*}{$\frac{\text { Binary ERG }}{M-W P \text { value }^{a}}$} & \multicolumn{2}{|c|}{ Mean Bin ERG } \\
\hline & & & $r$ & $P$ value ${ }^{\mathrm{b}}$ \\
\hline \multirow[t]{2}{*}{ MYC } & MYC & $<0.001$ & 0.437 & $<0.001$ \\
\hline & PIM2 & 0.001 & 0.231 & 0.002 \\
\hline \multirow[t]{4}{*}{ PI3K/AKT } & PTEN & 0.004 & -0.224 & 0.007 \\
\hline & INPP4B & 0.002 & -0.140 & 0.011 \\
\hline & P-AKT & 0.005 & 0.195 & 0.003 \\
\hline & P-GSK3B & 0.022 & 0.244 & $<0.001$ \\
\hline \multirow[t]{2}{*}{ NFאB } & NFкB p65 & 0.001 & 0.303 & $<0.001$ \\
\hline & NFKB P-S536 & $<0.001$ & 0.316 & $<0.001$ \\
\hline \multirow[t]{3}{*}{ Transcription } & p53 & 0.013 & 0.257 & $<0.001$ \\
\hline & SRF & $<0.001$ & 0.344 & $<0.001$ \\
\hline & SRC1 & 0.008 & 0.207 & 0.004 \\
\hline $\begin{array}{l}\text { Signal } \\
\text { transduction }\end{array}$ & Sprouty1 & 0.002 & 0.244 & 0.001 \\
\hline
\end{tabular}

${ }^{a}$ Mann-Whitney $U$ test comparing expression in ERG negative vs ERG positive.

'Spearman's rank correlation and associated $P$ value.

distance metric. The dendogram is shown in Fig. 4 with cases as columns showing the proportion of nuclei for each staining intensity (white, 0 and dark blue, 1.0). The largest cluster (negative; green) corresponds perfectly with the cases evaluated as negative by visual inspection. The visually positive staining cases are clustered into three groups, corresponding to low (blue), intermediate (orange), and strong (red) average staining. Most cases showed variable levels of staining within the tumor as well as between tumors when analyzed by image analysis. No strong association with pathological variables or biochemical recurrence was noted based on either the visual presence or absence of ERG, Mean Bin values, or cluster group (data not shown).

\section{Correlation of ERG expression with other proteins and biological processes in prostate cancer}

To better understand the biological influence of ERG expression and its variability in prostate cancer, we examined the correlation of ERG expression with the expression of proteins and biological factors in this same TMA given in Table 1. We compared marker levels between visually graded ERG groups and evaluated the correlations of these markers with Mean Bin ERG expression. The proteins that showed highly significant associations with ERG expression by both visual and quantitative methods of analysis are listed in Table 2. To be included in this table, associations detected using both methods of analysis had to be statistically significant $(P \leq 0.05)$ with at least one method being significant at
$P \leq 0.01$. Scatter plots demonstrating some of these associations are shown in Fig. 5.

The strongest correlation is with MYC expression $(r=0.437$; Fig. 5). Notably, MYC has been shown to be a direct transcriptional target of ERG (Sun et al. 2008) and
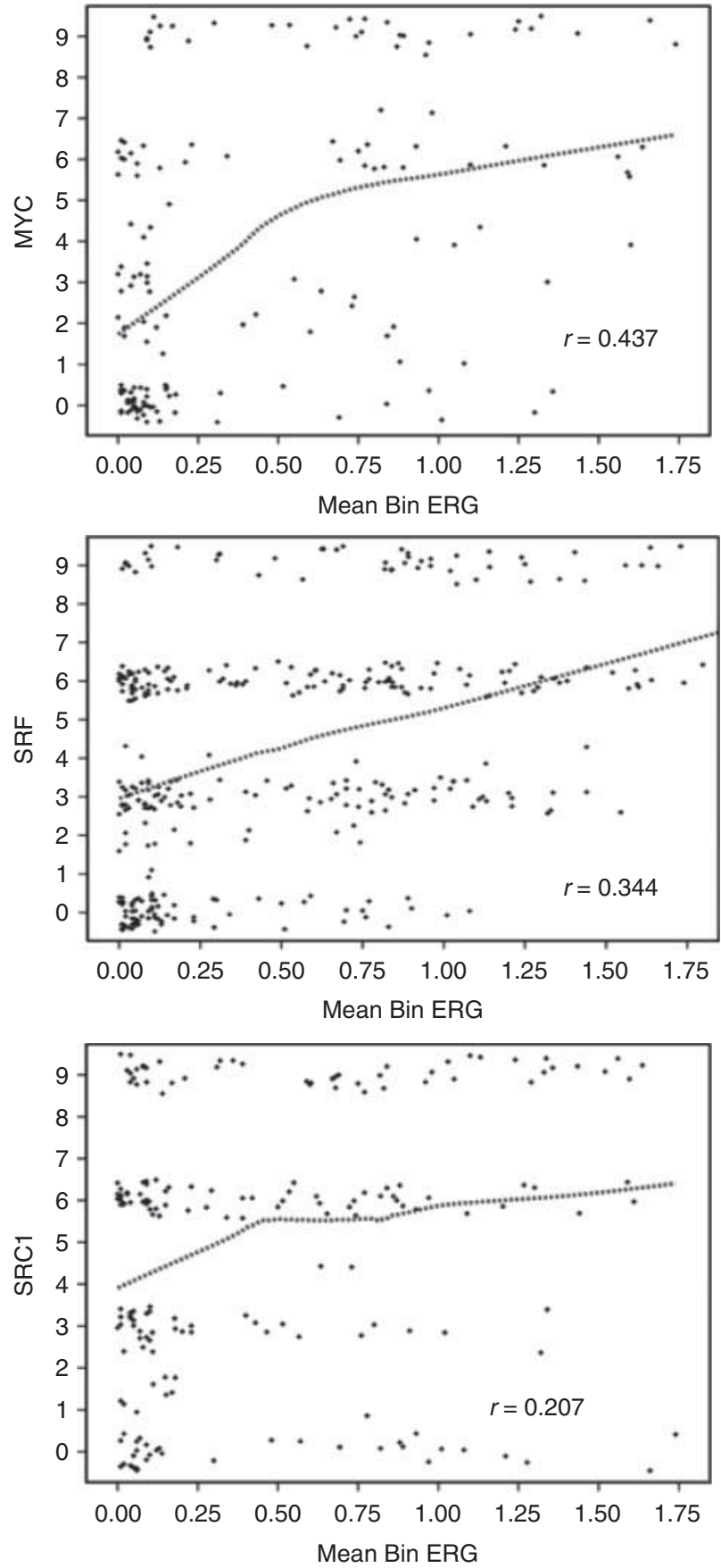

Figure 5

Relationship between expression of selected proteins and ERG. Scatter plots with conditional uniform jitter and Loess fit curve ( $75 \%$ of points) to illustrate the relationship between MYC, SRF, SRC1 and ERG.

The correlation coefficient $r$ is Spearman's rank.

Published by Bioscientifica Ltd 
our results are consistent with a significant role for ERG in driving MYC expression in primary prostate cancers. PIM2 is also correlated with ERG expression. While PIM2 has pleiotrophic effects on tumor progression, it can synergize with MYC overexpression (Allen et al. 1997), and this may be at least one of its important roles in prostate cancer, where MYC overexpression is common (Antonarakis et al. 2012).

As described previously, there is a significant positive correlation of ERG with increased levels of NFкB p65 phospho-Ser536, which is an indirect target of the ERG oncoprotein via its induction of TLR4. In addition, nuclear $\mathrm{NF \kappa B}$ p65 is correlated with ERG expression. This may be in part via increased PIM1 kinase, which has been reported to be increased by ERG (Magistroni et al. 2011), and is known to activate the NFאB pathway. PIM2 has also been linked to NFKB pathway activation (Dai et al. 2005).

ERG is negatively correlated with both PTEN and INPP4B (Table 2). Loss of the INPP4B phosphatase also activates the AKT pathway and is an alternative mode of activating this pathway in prostate cancer (Agoulnik et al. 2011). The association of ERG expression with loss of PTEN at the genomic level has been described previously, and loss of PTEN and expression of ERG synergize in prostate cancer induction in genetically engineered mouse models of prostate cancer. Our results confirm this association and indicate that there is also correlation with activation of the AKT pathway by alternative genomic alterations, and thus the observed association with PTEN loss is unlikely to be due to loss of other activities of PTEN (Bassi et al. 2013). Notably, in those cancers with ERG expression, low INPP4B levels were associated with a significantly decreased time to biochemical recurrence $(P=0.023, \mathrm{HR}=2.01,95 \% \mathrm{CI}(1.09$, 3.70), Fig. 6). There was no difference in ERG negative cases $(P=0.31)$. We did not see a similar association with PTEN levels (results not shown). Loss of PTEN has been associated with worse outcome in T/E-fusion-positive prostate cancer in some but not all studies (Reid et al. 2010, Leinonen et al. 2013). Consistent with these findings, ERG is positively associated with phosphorylated AKT (Ser473) and phosphorylated GSK3B. Taken together, these results are mutually consistent and indicate that ERG expression is broadly associated with activation of the PI3K pathway.

We have previously shown that SRF is increased in prostate cancer, and higher expression is associated with biochemical recurrence after radical prostatectomy (Yu et al. 2011). Results of recent studies have indicated that SRF is associated with aggressive metastatic disease as well (O'Hurley et al. 2014). Unexpectedly, we have found that SRF is significantly positively associated with ERG

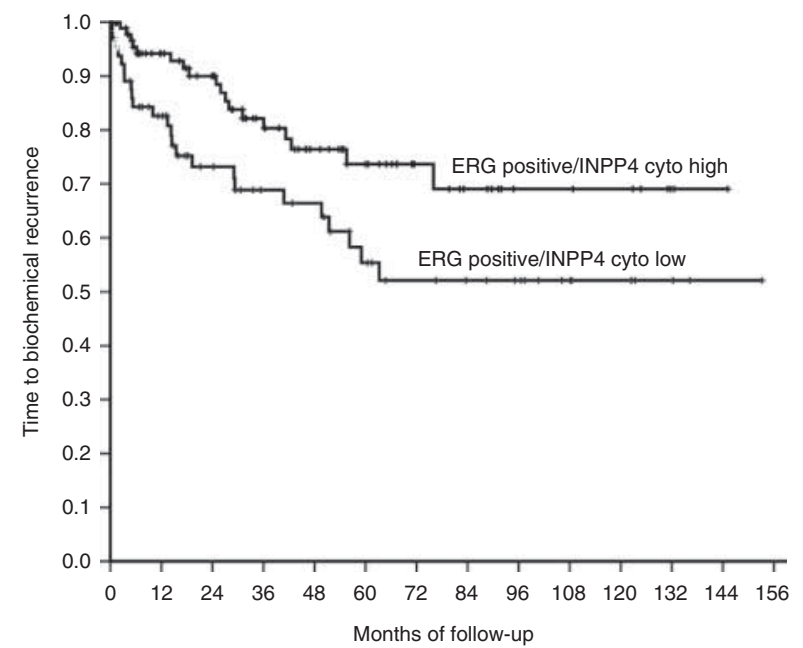

Figure 6

INPP4B loss decreases time to biochemical recurrence in prostate cancers expressing the TMPRSS2/ERG fusion gene. Kaplan-Meier analysis of time to biochemical recurrence following radical prostatectomy of ERG-positive cancers with low ('0-5', $n=65)$ or high (' $6-9$ ', $n=103)$ INPP4B index. The log-rank test for $P$ value is 0.023 .

expression and is the second strongest association $(r=0.344$; Fig. 5$)$ we identified (after MYC).

Expression of the p160 steroid receptor co-activator SRC1 is also positively correlated with ERG protein levels (Table 2 and Fig. 5). This positive association is most probably due the known role of SRC1 in promoting TMPRSS2 (and presumably T/E fusion gene) expression (Nakka et al. 2013).

The p53 pathway is among the most commonly altered pathways in cancer and although p53 mutation is uncommon in clinically localized cancer, we noted a positive correlation between ERG and p53. An increase in the expression of p53 protein is generally seen when this pathway is inactivated by mutation or some other mechanisms. Others have previously noted a correlation between the presence of the $T / E$ fusion gene and p53 protein expression (Minner et al. 2011, Kluth et al. 2014).

An increase in the expression of Sprouty 1 is associated with ERG expression. We have previously shown significant heterogeneity of Sprouty1 expression in prostate cancer with some cases being negative and other cases retaining staining or having increased staining compared with benign epithelium (Kwabi-Addo et al. 2004). The reason why ERG-expressing cancers would express Sprouty1 is not known, but ETS transcription factors are known to play an important role in Sprouty gene expression (Tsang \& Dawid 2004) and therefore it may be a direct target for ERG. Sprouty1 is known to inhibit FGF

Published by Bioscientifica Ltd. 
Table 3 Markers associated with ERG expression levels

\begin{tabular}{l} 
Protein or P-protein \\
\hline SKP2 \\
NFKB P-S536 \\
Sprouty1 \\
SRF
\end{tabular}

$\boldsymbol{r}$
0.291
0.328
0.244
0.274

\begin{tabular}{r} 
P value $^{\mathrm{a}}$ \\
\hline 0.003 \\
$<0.001$ \\
0.001 \\
0.002
\end{tabular}

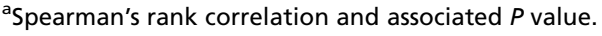

receptor signaling, but can enhance EGFR signaling (Tsang \& Dawid 2004), therefore some ERG-expressing cancers may have enhanced EGFR signaling via this mechanism.

\section{Associations with ERG protein levels}

To determine whether there is a unique biology associated with different levels of ERG protein as determined by image analysis, we examined the association of ERG protein levels with the 46 proteins/phosphoproteins and biological processes given in Table 1, excluding all cases that were ERG-negative (green cluster, Fig. 4). Thus all associations are driven by differences in ERG protein level between positive cases. Results of this analysis are given in Table 3, which lists the factors strongly associated with higher ERG expression $(P<0.01)$. Of note, most of the factors in Table 2 are no longer strongly significant except for NFкB p65 phospho-Ser536, SRF, and Sprouty1. SKP2 is identified as a novel factor associated with ERG protein levels. Thus differential ERG protein expression levels are associated with the activation of distinct pathways and proteins that are distinct from the pathways linked to the presence of ERG per se.

\section{Discussion}

Prostate cancer expressing the TMPRSS2/ERG fusion gene is by far the most commonly identified prostate cancer variant, and understanding how this fusion affects carcinogenesis is critical in developing novel approaches for therapy in men with prostate cancers bearing this fusion gene. We have analyzed associations 46 proteins/ phosphoproteins or biological process with the presence and level of ERG protein in clinically localized prostate cancer and identified multiple key proteins and pathways that are associated with the expression and/or level of expression of ERG. Such associations may reflect different types of underlying biology. One potential cause of such association is if the identified protein drives the expression of the fusion gene, as is probably the case for SRC1 (Nakka et al. 2013). Alternatively, the $E R G$ fusion gene may directly drive transcription of a protein (such as MYC) or indirectly drive increased expression (NFאB p65 phosphoSer536 via TLR4). In addition, such associations may be due to selection of strong biological complementation of a pathway/protein with ERG expression, as is apparently the case for the PI3K/AKT pathway. Finally, it is possible that some observed associations may be due to chance, as may occur with examination of multiple associations, although our stringent $P$ values make this less likely. At present the exact mechanisms underlying many of the associations we have identified will require further study. However, we have confirmed using human tissues some previously inferred associations based on mechanistic data (MYC), identified new associations related to prior identified associations (INPP4B, NFאB, and PIM2) and also identified novel associations (SRF, Sprouty1). These associations in human cancers provide a strong rationale for further mechanistic studies.

On the basis of the results of quantitative image analysis, our studies confirm that there is interfocal and intrafocal variability in ERG protein levels in prostate cancer. Early studies had shown that different cancer foci in radical prostatectomy specimens were discordant for the presence of the fusion gene in some cases (Mehra et al. 2007). This is well established and we have not examined this question in the current studies. In contrast, our studies of both the radical prostatectomy specimens and in the TMAs examine only a single cancer focus in each radical prostatectomy. We now show objectively that there is heterogeneity in overall levels of ERG protein expression in different patients. Such heterogeneity may arise due to germline variability between patients and/or genomic variability between cancers. For example, germline variants of the TMPRSS2 enhancer affecting AR binding (Clinckemalie et al. 2013), germline $A R$ variants, and or germline variants affecting androgen synthesis and/or metabolism may all potentially affect $\mathrm{T} / \mathrm{E}$ fusion protein levels. Vitamin $D$ can also increase transcription of the $T / E$ fusion gene (Washington \& Weigel 2010) and individual variation in vitamin D metabolism and/or intake may also potentially influence fusion gene expression. The variable levels of coactivators (such as SRC1 and potentially others) may also affect transcription. Differential miRNA expression between different cancers may also affect ERG levels because miRNAs targeting the $T / E$ fusion have been identified (Hart et al. 2013). In any case, we have previously shown marked variability in levels of fusion gene mRNA in different fusion-gene-expressing cancers (Wang et al. 2006), so some of the variability between different patient's cancers is almost certainly due to differential levels of

Published by Bioscientifica Ltd. 
transcription and/or mRNA stability in those tumors. We have also described significant differences in alternative splicing in different cancers, which can affect translational efficiency (Zammarchi et al. 2013); therefore, translational alterations must also be considered. Differences in protein stability or degradation based on differences in alternatively spliced isoforms or associated tumor alterations may also play a role.

We also observed significant differences in ERG levels within a single cancer lesion. The finding that expression was stronger at the edge of some tumors indicates that invasion, proliferation, or local microenvironmental factors may modulate ERG expression.

Alternatively, genomic heterogeneity within cancers, including prostate cancer, is well known, and other genomic alterations may be heterogeneous within a given cancer focus and this could affect ERG protein levels. Further studies are needed to determine the basis of intrafocal heterogeneity in fusion gene protein levels in prostate cancer.

The influence of different levels of ERG protein on the biology of fusion-gene-expressing cancers is not completely clear. The core proteins/pathways identified in our study (Table 2) appear to be associated with any level of ERG protein expression, because the associations are present even when tumors are classified based on visual detection of any ERG protein in cancer cells. However, the associations noted with variable ERG expression are different and only partially overlapping. Thus there is probably significant similarity in the biology of all ERG-expressing prostate cancers but also some differences. The differences may be important is some contexts. For example, NFкB p65 phospho-Ser536 levels are positively correlated with the levels of ERG protein, which indicates that cancers with high ERG protein may be more sensitive to therapies targeting the NFkB pathway. We did not observe any differences in clinical outcome related to the levels of ERG expression. However, results from a recent study of a radical prostatectomy cohort enriched for highly aggressive disease have indicated that higher levels of ERG protein are significantly associated with distant metastasis and death of prostate cancer cells (Spencer et al. 2013). Notably, in this study, the presence of ERG protein per se was not associated with aggressive prostate cancer, concordant with the results of most, but not all, studies of radical prostatectomy cohorts to date. It is possible that our study is underpowered for detecting such associations because the majority of our cases were not aggressive. Additional studies of larger cohorts with larger numbers of aggressive cancers will be therefore needed to determine whether the levels of ERG expression influence clinical outcome.

\section{Declaration of interest}

The authors declare that there is no conflict of interest that could be perceived as prejudicing the impartiality of the research reported.

\section{Funding}

This work was supported by grant R01CA140734 from the National Cancer Institute (G Ayala), the Dan L. Duncan Cancer Center P30 Cancer Center support grant (P30 CA125123) supporting the Human Tissue Acquisition and Pathology Core and the Biostatistics and Bioinformatics Core, the Department of Veterans Affairs Merit Review program (M Ittmann) and by the use of the facilities of the Michael E. DeBakey VA Medical Center.

\section{Acknowledgements}

The technical assistance of Billie Smith and the Human Tissue Acquisition and Pathology Core of the Dan L. Duncan Cancer Center is gratefully acknowledged.

\section{References}

Agoulnik IU, Krause WC, Bingman WE III, Rahman HT, Amrikachi M, Ayala GE \& Weigel NL 2003 Repressors of androgen and progesterone receptor action. Journal of Biological Chemistry 278 31136-31148. (doi:10.1074/jbc.M305153200)

Agoulnik IU, Vaid A, Bingman WE III, Erdeme H, Frolov A, Smith CL, Ayala G, Ittmann MM \& Weigel NL 2005 Role of SRC-1 in the promotion of prostate cancer cell growth and tumor progression. Cancer Research 65 7959-7967. (doi:10.1158/0008-5472.CAN-04-3541)

Agoulnik IU, Vaid A, Nakka M, Alvarado M, Bingman WE III, Erdem H, Frolov A, Smith CL, Ayala GE, Ittmann MM et al. 2006 Androgens modulate expression of transcription intermediary factor 2 , an androgen receptor coactivator whose expression level correlates with early biochemical recurrence in prostate cancer. Cancer Research 66 10594-10602. (doi:10.1158/0008-5472.CAN-06-1023)

Agoulnik IU, Hodgson MC, Bowden WA \& Ittmann MM 2011 INPP4B: the new kid on the PI3K block. Oncotarget 2 321-328.

Allen JD, Verhoeven E, Domen J, van der Valk M \& Berns A 1997 Pim-2 transgene induces lymphoid tumors, exhibiting potent synergy with c-myc. Oncogene 15 1133-1141. (doi:10.1038/sj.onc.1201288)

Antonarakis ES, Keizman D, Zhang Z, Gurel B, Lotan TL, Hicks JL, Fedor HL, Carducci MA, De Marzo AM \& Eisenberger MA 2012 An immunohistochemical signature comprising PTEN, MYC, and Ki67 predicts progression in prostate cancer patients receiving adjuvant docetaxel after prostatectomy. Cancer 118 6063-6071. (doi:10.1002/cncr.27689)

Ayala G, Tuxhorn JA, Wheeler TM, Frolov A, Scardino PT, Ohori M, Wheeler M, Spitler J \& Rowley DR 2003a Reactive stroma as a predictor of biochemical-free recurrence in prostate cancer. Clinical Cancer Research 9 4792-4801.

Ayala G, Wang D, Wulf G, Frolov A, Li R, Sowadski J, Wheeler TM, Lu KP \& Bao L $2003 b$ The prolyl isomerase Pin 1 is a novel prognostic marker in human prostate cancer. Cancer Research 63 6244-6251.

Ayala G, Thompson T, Yang G, Frolov A, Li R, Scardino P, Ohori M, Wheeler T \& Harper W 2004 High levels of phosphorylated form of Akt-1 in prostate cancer and non-neoplastic prostate tissues are strong predictors of biochemical recurrence. Clinical Cancer Research 10 6572-6578. (doi:10.1158/1078-0432.CCR-04-0477) 
Ayala G, Frolov A, Ittman M, Mohammed S, LeBlanc M, Falcon S, Rowley D \& Etzioni R 2013a Biological correlates of biochemical recurrence free survival using multiple markers in a large tissue microarray cohort. Annals of Clinical and Laboratory Science 43 11-21.

Ayala G, Morello M, Frolov A, You S, Li R, Rosati F, Bartolucci G, Danza G, Adam RM, Thompson TC et al. 2013b Loss of caveolin-1 in prostate cancer stroma correlates with reduced relapse-free survival and is functionally relevant to tumour progression. Journal of Pathology $\mathbf{2 3 1}$ 77-87. (doi:10.1002/path.4217)

Bassi C, Ho J, Srikumar T, Dowling RJ, Gorrini C, Miller SJ, Mak TW, Neel BG, Raught B \& Stambolic V 2013 Nuclear PTEN controls DNA repair and sensitivity to genotoxic stress. Science 341 395-399. (doi:10.1126/ science.1236188)

Brase JC, Johannes M, Mannsperger H, Falth M, Metzger J, Kacprzyk LA, Andrasiuk T, Gade S, Meister M, Sirma H et al. 2011 TMPRSS2-ERGspecific transcriptional modulation is associated with prostate cancer biomarkers and TGF- $\beta$ signaling. BMC Cancer 11 507. (doi:10.1186/ 1471-2407-11-507)

Cai C, Wang H, He HH, Chen S, He L, Ma F, Mucci L, Wang Q, Fiore C, Sowalsky AG et al. 2013 ERG induces androgen receptor-mediated regulation of SOX9 in prostate cancer. Journal of Clinical Investigation 123 1109-1122. (doi:10.1172/JCI66666)

Chen Y, Chi P, Rockowitz S, Iaquinta PJ, Shamu T, Shukla S, Gao D, Sirota I, Carver BS, Wongvipat J et al. 2013 ETS factors reprogram the androgen receptor cistrome and prime prostate tumorigenesis in response to PTEN loss. Nature Medicine 19 1023-1029. (doi:10.1038/nm.3216)

Clinckemalie L, Spans L, Dubois V, Laurent M, Helsen C, Joniau S \& Claessens F 2013 Androgen regulation of the TMPRSS2 gene and the effect of a SNP in an androgen response element. Molecular Endocrinology 27 2028-2040. (doi:10.1210/me.2013-1098)

Cordon-Cardo C, Kotsianti A, Verbel DA, Teverovskiy M, Capodieci P, Hamann S, Jeffers Y, Clayton M, Elkhettabi F, Khan FM et al. 2007 Improved prediction of prostate cancer recurrence through systems pathology. Journal of Clinical Investigation 117 1876-1883. (doi:10.1172/JCI31399)

Dai H, Li R, Wheeler T, Diaz de Vivar A, Frolov A, Tahir S, Agoulnik I, Thompson T, Rowley D \& Ayala G 2005 Pim-2 upregulation: biological implications associated with disease progression and perinueral invasion in prostate cancer. Prostate 65 276-286. (doi:10.1002/pros. 20294)

Ding Y, He D, Florentin D, Frolov A, Hilsenbeck S, Ittmann M, Kadmon D, Miles B, Rowley D \& Ayala G 2013 Semaphorin 4F as a critical regulator of neuroepithelial interactions and a biomarker of aggressive prostate cancer. Clinical Cancer Research 19 6101-6111. (doi:10.1158/10780432.CCR-12-3669)

Gupta S, Iljin K, Sara H, Mpindi JP, Mirtti T, Vainio P, Rantala J, Alanen K, Nees M \& Kallioniemi O 2010 FZD4 as a mediator of ERG oncogeneinduced WNT signaling and epithelial-to-mesenchymal transition in human prostate cancer cells. Cancer Research 70 6735-6745. (doi:10.1158/0008-5472.CAN-10-0244)

Han B, Mehra R, Lonigro RJ, Wang L, Suleman K, Menon A, Palanisamy N, Tomlins SA, Chinnaiyan AM \& Shah RB 2009 Fluorescence in situ hybridization study shows association of PTEN deletion with ERG rearrangement during prostate cancer progression. Modern Pathology 22 1083-1093. (doi:10.1038/modpathol.2009.69)

Haqq C, Li R, Khodabakhsh D, Frolov A, Ginzinger D, Thompson T, Wheeler T, Carroll P \& Ayala G 2005 Ethnic and racial differences in prostate stromal estrogen receptor $\alpha$. Prostate 65 101-109. (doi:10.1002/ pros.20272)

Hart M, Wach S, Nolte E, Szczyrba J, Menon R, Taubert H, Hartmann A, Stoehr R, Wieland W, Grasser FA et al. 2013 The proto-oncogene ERG is a target of microRNA $m i R-145$ in prostate cancer. FEBS Journal $\mathbf{2 8 0}$ 2105-2116. (doi:10.1111/febs.12236)

Hodgson MC, Shao LJ, Frolov A, Li R, Peterson LE, Ayala G, Ittmann MM, Weigel NL \& Agoulnik IU 2011 Decreased expression and androgen regulation of the tumor suppressor gene INPP4B in prostate cancer. Cancer Research 71 572-582. (doi:10.1158/0008-5472.CAN-10-2314)

King JC, Xu J, Wongvipat J, Hieronymus H, Carver BS, Leung DH, Taylor BS, Sander C, Cardiff RD, Couto SS et al. 2009 Cooperativity of TMPRSS2$E R G$ with PI3-kinase pathway activation in prostate oncogenesis. Nature Genetics 41 524-526. (doi:10.1038/ng.371)

Kluth M, Harasimowicz S, Burkhardt L, Grupp K, Krohn A, Prien K, Gjoni J, Hass T, Galal R, Graefen M et al. 2014 Clinical significance of different types of $p 53$ gene alteration in surgically treated prostate cancer. International Journal of Cancer. Journal International du Cancer $\mathbf{1 3 5}$ 1369-1380. (doi:10.1002/ijc.28784)

Knudsen BS, Lucas JM, Fazli L, Hawley S, Falcon S, Coleman IM, Martin DB, $\mathrm{Xu}$ C, True LD, Gleave ME et al. 2005 Regulation of hepatocyte activator inhibitor-1 expression by androgen and oncogenic transformation in the prostate. American Journal of Pathology 167 255-266. (doi:10.1016/ S0002-9440(10)62970-7)

Kwabi-Addo B, Wang J, Erdem H, Vaid A, Castro P, Ayala G \& Ittmann M 2004 The expression of Sprouty1, an inhibitor of fibroblast growth factor signal transduction, is decreased in human prostate cancer. Cancer Research 64 4728-4735. (doi:10.1158/0008-5472.CAN-03-3759)

Leinonen KA, Saramaki OR, Furusato B, Kimura T, Takahashi H, Egawa S, Suzuki H, Keiger K, Ho Hahm S, Isaacs WB et al. 2013 Loss of PTEN is associated with aggressive behavior in ERG-positive prostate cancer. Cancer Epidemiology, Biomarkers \& Prevention 22 2333-2344. (doi:10. 1158/1055-9965.EPI-13-0333-T)

Li R, Younes M, Frolov A, Wheeler TM, Scardino P, Ohori M \& Ayala G 2003 Expression of neutral amino acid transporter ASCT2 in human prostate. Anticancer Research 23 3413-3418.

Li R, Wheeler T, Dai H, Frolov A, Thompson T \& Ayala G 2004a High level of androgen receptor is associated with aggressive clinicopathologic features and decreased biochemical recurrence-free survival in prostate: cancer patients treated with radical prostatectomy. American Journal of Surgical Pathology 28 928-934. (doi:10.1097/00000478-20040700000013)

Li R, Younes M, Wheeler TM, Scardino P, Ohori M, Frolov A \& Ayala G $2004 b$ Expression of vascular endothelial growth factor receptor-3 (VEGFR-3) in human prostate. Prostate 58 193-199. (doi:10.1002/pros. 10321)

Li R, Wheeler TM, Dai H, Sayeeduddin M, Scardino PT, Frolov A \& Ayala GE 2006 Biological correlates of p27 compartmental expression in prostate cancer. Journal of Urology 175 528-532. (doi:10.1016/S00225347(05)00151-5)

Li R, Erdamar S, Dai H, Wheeler TM, Frolov A, Scardino PT, Thompson TC \& Ayala GE 2007 Forkhead protein FKHR and its phosphorylated form p-FKHR in human prostate cancer. Human Pathology 38 1501-1507. (doi:10.1016/j.humpath.2007.02.016)

Li R, Dai H, Wheeler TM, Sayeeduddin M, Scardino PT, Frolov A \& Ayala GE $2009 a$ Prognostic value of Akt-1 in human prostate cancer: a computerized quantitative assessment with quantum dot technology. Clinical Cancer Research 15 3568-3573. (doi:10.1158/1078-0432.CCR08-0826)

Li R, Erdamar S, Dai H, Sayeeduddin M, Frolov A, Wheeler TM \& Ayala GE $2009 b$ Cytoplasmic accumulation of glycogen synthase kinase- $3 \beta$ is associated with aggressive clinicopathological features in human prostate cancer. Anticancer Research 29 2077-2081.

Lin B, Ferguson C, White JT, Wang S, Vessella R, True LD, Hood L \& Nelson PS 1999 Prostate-localized and androgen-regulated expression of the membrane-bound serine protease TMPRSS2. Cancer Research 59 4180-4184

Magistroni V, Mologni L, Sanselicio S, Reid JF, Redaelli S, Piazza R, Viltadi M, Bovo G, Strada G, Grasso M et al. 2011 ERG deregulation induces PIM1 over-expression and aneuploidy in prostate epithelial cells. PLOS ONE 6 e28162. (doi:10.1371/journal.pone.0028162)

Massoner P, Kugler KG, Unterberger K, Kuner R, Mueller LA, Falth M, Schafer G, Seifarth C, Ecker S, Verdorfer I et al. 2013 Characterization of transcriptional changes in ERG rearrangement-positive prostate cancer 
identifies the regulation of metabolic sensors such as neuropeptide $\mathrm{Y}$ PLOS ONE 8 e55207. (doi:10.1371/journal.pone.0055207)

McAlhany SJ, Ayala GE, Frolov A, Ressler SJ, Wheeler TM, Watson JE, Collins C \& Rowley DR 2004 Decreased stromal expression and increased epithelial expression of WFDC1/ps20 in prostate cancer is associated with reduced recurrence-free survival. Prostate 61 182-191. (doi:10.1002/pros.20085)

Mehra R, Han B, Tomlins SA, Wang L, Menon A, Wasco MJ, Shen R, Montie JE, Chinnaiyan AM \& Shah RB 2007 Heterogeneity of TMPRSS2 gene rearrangements in multifocal prostate adenocarcinoma: molecular evidence for an independent group of diseases. Cancer Research 67 7991-7995. (doi:10.1158/0008-5472.CAN-07-2043)

Mertz KD, Horcic M, Hailemariam S, D'Antonio A, Dirnhofer S, Hartmann A, Agaimy A, Eppenberger-Castori S, Obermann E, Cathomas G et al. 2013 Heterogeneity of ERG expression in core needle biopsies of patients with early prostate cancer. Human Pathology 44 2727-2735. (doi:10.1016/ j.humpath.2013.07.019)

Minner S, Enodien M, Sirma H, Luebke AM, Krohn A, Mayer PS, Simon R, Tennstedt P, Muller J, Scholz L et al. 2011 ERG status is unrelated to PSA recurrence in radically operated prostate cancer in the absence of antihormonal therapy. Clinical Cancer Research 17 5878-5888. (doi:10.1158/1078-0432.CCR-11-1251)

Minner S, Gartner M, Freudenthaler F, Bauer M, Kluth M, Salomon G, Heinzer H, Graefen M, Bokemeyer C, Simon R et al. 2013 Marked heterogeneity of ERG expression in large primary prostate cancers. Modern Pathology 26 106-116. (doi:10.1038/modpathol.2012.130)

Nakka M, Agoulnik IU \& Weigel NL 2013 Targeted disruption of the p160 coactivator interface of androgen receptor (AR) selectively inhibits AR activity in both androgen-dependent and castration-resistant AR-expressing prostate cancer cells. International Journal of Biochemistry \& Cell Biology 45 763-772. (doi:10.1016/j.biocel.2012.12.012)

O'Hurley G, Prencipe M, Lundon D, O'Neill A, Boyce S, O'Grady A, Gallagher WM, Morrissey C, Kay EW \& Watson RW 2014 The analysis of serum response factor expression in bone and soft tissue prostate cancer metastases. Prostate 74 306-313. (doi:10.1002/pros.22752)

Park K, Tomlins SA, Mudaliar KM, Chiu YL, Esgueva R, Mehra R, Suleman K, Varambally S, Brenner JC, MacDonald T et al. 2010 Antibody-based detection of $E R G$ rearrangement-positive prostate cancer. Neoplasia 12 590-598. (doi:10.1593/neo.10726)

Qin J, Wu SP, Creighton CJ, Dai F, Xie X, Cheng CM, Frolov A, Ayala G, Lin X, Feng XH et al. 2013 COUP-TFII inhibits TGF- $\beta$-induced growth barrier to promote prostate tumorigenesis. Nature 493 236-240. (doi:10.1038/ nature11674)

Reid AH, Attard G, Ambroisine L, Fisher G, Kovacs G, Brewer D, Clark J, Flohr P, Edwards S, Berney DM et al. 2010 Molecular characterisation of ERG, ETV1 and PTEN gene loci identifies patients at low and high risk of death from prostate cancer. British Journal of Cancer 102 678-684. (doi:10.1038/sj.bjc.6605554)

Shao L, Tekedereli I, Wang J, Yuca E, Tsang S, Sood A, Lopez-Berestein G, Ozpolat B \& Ittmann M 2012 Highly specific targeting of the TMPRSS2/ERG fusion gene using liposomal nanovectors. Clinical Cancer Research 18 6648-6657. (doi:10.1158/1078-0432.CCR-12-2715)

Spencer ES, Johnston RB, Gordon RR, Lucas JM, Ussakli CH, Hurtado-Coll A, Srivastava S, Nelson PS \& Porter CR 2013 Prognostic value of ERG oncoprotein in prostate cancer recurrence and cause-specific mortality. Prostate 73 905-912. (doi:10.1002/pros.22636)

Sun C, Dobi A, Mohamed A, Li H, Thangapazham RL, Furusato B, Shaheduzzaman S, Tan SH, Vaidyanathan G, Whitman E et al. 2008 TMPRSS2-ERG fusion, a common genomic alteration in prostate cancer activates $C-M Y C$ and abrogates prostate epithelial differentiation. Oncogene 27 5348-5353. (doi:10.1038/onc.2008.183)
Tian TV, Tomavo N, Huot L, Flourens A, Bonnelye E, Flajollet S, Hot D, Leroy X, de Launoit Y \& Duterque-Coquillaud M 2013 Identification of novel TMPRSS2:ERG mechanisms in prostate cancer metastasis: involvement of MMP9 and PLXNA2. Oncogene 33 2204-2214. (doi:10.1038/onc.2013.176)

Tomlins SA, Rhodes DR, Perner S, Dhanasekaran SM, Mehra R, Sun XW, Varambally S, Cao X, Tchinda J, Kuefer R et al. 2005 Recurrent fusion of TMPRSS2 and ETS transcription factor genes in prostate cancer. Science 310 644-648. (doi:10.1126/science.1117679)

Tomlins SA, Laxman B, Varambally S, Cao X, Yu J, Helgeson BE, Cao Q, Prensner JR, Rubin MA, Shah RB et al. 2008 Role of the TMPRSS2-ERG gene fusion in prostate cancer. Neoplasia 10 177-188. (doi:10.1593/ neo.07822)

Tsang M \& Dawid IB 2004 Promotion and attenuation of FGF signaling through the Ras-MAPK pathway. Science's STKE: Signal Transduction Knowledge Environment 2004 pe17. (doi:10.1126/stke.2282004pe17)

Vainio P, Lehtinen L, Mirtti T, Hilvo M, Seppanen-Laakso T, Virtanen J, Sankila A, Nordling S, Lundin J, Rannikko A et al. 2011 Phospholipase PLA2G7, associated with aggressive prostate cancer, promotes prostate cancer cell migration and invasion and is inhibited by statins. Oncotarget 2 1176-1190.

Wang J, Cai Y, Ren C \& Ittmann M 2006 Expression of variant TMPRSS2/ERG fusion messenger RNAs is associated with aggressive prostate cancer. Cancer Research 66 8347-8351. (doi:10.1158/00085472.CAN-06-1966)

Wang J, Cai Y, Yu W, Ren C, Spencer DM \& Ittmann M 2008 Pleiotropic biological activities of alternatively spliced TMPRSS2/ERG fusion gene transcripts. Cancer Research 68 8516-8524. (doi:10.1158/0008-5472. CAN-08-1147)

Wang J, Cai Y, Shao LJ, Siddiqui J, Palanisamy N, Li R, Ren C, Ayala G \& Ittmann M 2011 Activation of NF-кB by TMPRSS2/ERG fusion isoforms through Toll-like receptor-4. Cancer Research 71 1325-1333. (doi:10.1158/0008-5472.CAN-10-2210)

Washington MN \& Weigel NL 2010 1 $\alpha, 25$-Dihydroxyvitamin $\mathrm{D}_{3}$ inhibits growth of VCaP prostate cancer cells despite inducing the growthpromoting TMPRSS2:ERG gene fusion. Endocrinology 151 1409-1417. (doi:10.1210/en.2009-0991)

Wu L, Zhao JC, Kim J, Jin HJ, Wang CY \& Yu J 2013 ERG is a critical regulator of Wnt/LEF1 signaling in prostate cancer. Cancer Research $\mathbf{7 3}$ 6068-6079. (doi:10.1158/0008-5472.CAN-13-0882)

Yang G, Ayala G, De Marzo A, Tian W, Frolov A, Wheeler TM, Thompson TC \& Harper JW 2002 Elevated Skp2 protein expression in human prostate cancer: association with loss of the cyclin-dependent kinase inhibitor p27 and PTEN and with reduced recurrence-free survival. Clinical Cancer Research 8 3419-3426.

Yu J, Mani RS, Cao Q, Brenner CJ, Cao X, Wang X, Wu L, Li J, Hu M, Gong Y et al. 2010 An integrated network of androgen receptor, polycomb, and TMPRSS2-ERG gene fusions in prostate cancer progression. Cancer Cell 17 443-454. (doi:10.1016/j.ccr.2010.03.018)

Yu W, Feng S, Dakhova O, Creighton CJ, Cai Y, Wang J, Li R, Frolov A, Ayala G \& Ittmann M 2011 FGFR-4 Arg $^{388}$ enhances prostate cancer progression via extracellular signal-related kinase and serum response factor signaling. Clinical Cancer Research 17 4355-4366. (doi:10.1158/ 1078-0432.CCR-10-2858)

Zammarchi F, Boutsalis G \& Cartegni L 2013 5' UTR control of native ERG and of Tmprss2:ERG variants activity in prostate cancer. PLOS ONE $\mathbf{8}$ e49721. (doi:10.1371/journal.pone.0049721)

Zhou HJ, Yan J, Luo W, Ayala G, Lin SH, Erdem H, Ittmann M, Tsai SY \& Tsai MJ 2005 SRC-3 is required for prostate cancer cell proliferation and survival. Cancer Research 65 7976-7983. (doi:10.1158/0008-5472. CAN-04-4076)

Received in final form 23 February 2015

Accepted 25 February 2015 http://erc.endocrinology-journals.org

DOI: $10.1530 /$ ERC-14-0586
(C) 2015 Society for Endocrinology Printed in Great Britain
Published by Bioscientifica Ltd 